\title{
IMPORTANT SEVERE ACCIDENT RESEARCH ISSUES AFTER ACCIDENT AT FUKUSHIMA DAIICHI NUCLEAR POWER STATION
}

\author{
SUGIMOTO, Jun \\ Kyoto University \\ Kyoto, JAPAN
}

\begin{abstract}
After the accident at Fukushima Daiichi Nuclear Power Station several investigation committees issued reports with lessons learned from the accident in Japan. Among those lessons, some recommendations have been made on severe accident research. Similar to the EURSAFE efforts under EU Program, review of specific severe accident research items was started before Fukushima accident in working group of Atomic Energy Society of Japan (AESJ) in terms of significance of consequences, uncertainties of phenomena and maturity of assessment methodology. Re-investigation has been started after the Fukushima accident in this working group. Additional effects of Fukushima accident, such as core degradation behaviors, sea water injection, containment failure/leakage and re-criticality have been covered. The review results are categorized in ten major fields; core degradation behavior, core melt coolability/retention in containment vessel, function of containment vessel, source term, hydrogen behavior, fuelcoolant interaction, molten core concrete interaction, direct containment heating, recriticality and instrumentation in severe accident conditions. In January 2012, Research Expert Committee on Evaluation of Severe Accident was established in AESJ in order to investigate severe accident related issues for future LWR development and to propose action plans for future severe accident research, in collaboration with this working group. Based on these activities and also author's personal view, the present paper describes the perspective of important severe accident research issues after Fukushima accident. Specifically those are investigation of damaged core and components, advanced severe accident analysis capabilities and associated experimental investigations, development of reliable passive cooling system for core/containment, analysis of hydrogen behavior and investigation of hydrogen measures, enhancement of removal function of radioactive materials of containment venting, advanced instrumentation for the diagnosis of severe accident and assessment of advanced
\end{abstract}

containment design which excludes long-term evacuation in any severe accident situations.

\section{INTRODUCTION}

Severe accident research in Japan was started after TMI-2 accident with small-scale experiments and analysis and it was accelerated after Chernobyl accident with relatively large-scale experiment and analysis until around 2005. In response to "Recommendation of Accident management for severe accident of light water nuclear power plant" by Nuclear Safety Committee of Japan in 1992, basic policy of accident management measures due to internal events was proposed by electric power companies and they were approved by the Government in 1994. After the deployment of accident management measures at nuclear power plants until around 2004, severe accident research was drastically reduced in term of number of experts and budget in Japan. Also severe accident due to external events has not been paid careful attention for the accident management measures, even though the knowledge and methodologies on severe accident initiated by the external events has been accumulated in recent years.

After the accident at Fukushima Daiichi Nuclear Power Station (Fukushima accident) several investigation committees have been established, such as by the Government, Diet and private sectors including Tokyo Electric Power Company. They have issued investigation reports with lessons learned from the accident [1]-[7]. For example, Japanese Government made report to IAEA Ministerial Conference on Nuclear Safety in June 2011 with 28 lessons learned [2]. Several measures, such as enhanced power supply capabilities and improved severe accident management, have already been in place based on the lessons learned and some mid/long term measures are being implemented at nuclear power plant sites in Japan. Among those lessons, several recommendations have been made on severe accident research.

Under EU Program, European expert network for the reduction of uncertainties in severe accident safety issues 
(EURSAFE) has been established and it created the phenomena identification and ranking tables (PIRT) on all aspects of severe accident[8][9]. Specific severe accident research items have also been reviewed by working group of Atomic Energy Society of Japan (AESJ) in terms of significance of consequences, uncertainties of phenomena and maturity of assessment methodology [10]. Based on these activities and also author's personal view, the present paper describes the current status and perspective of important severe accident research issues after Fukushima accident [11] [12].

\section{SEVEREACCIDEENT RELATED LESSONS LEARNED FROM FUKUSHIMA ACCIDENT}

2.1 Investigation reports issued

After the Fukushima accident several investigation committees have been established and the following reports have been issued in Japan:

(1) Atomic Energy Society of Japan, May 2011 (AESJ) [1]

(2) Japanese Government to IAEA Ministerial Conference on Nuclear Safety, June 2011 (Japanese Government) [2]

(3) Advisory Committee for Prevention of Nuclear Accident, December 2011(Advisory Committee) [3]

(4) Independent Investigation Commission, Feb 2012 (Nongovernment Committee) [4]

(5) Tokyo Electric Power Company, June 2012 (TEPCO Committee) [5]

(6) National Diet of Japan Investigation Commission, July 2012 (Diet Committee) [6]

(7) Investigation Committee on the Accident, July 2012 (Government Committee) [7]

Major almost common technical lessons learned from the accident in these reports are as follows:

(1) Enhanced measures against extreme external events, such as earthquake and tsunami

(2) Ensuring of emergency power supplies in terms of diversity and reliability

(3) Enhanced cooling capabilities of reactor core and containment vessel by passive features

(4) Improved preventive and mitigative severe accident management measures, including hydrogen control and containment venting

(5) Improved preparedness and responses to disaster condition in multiple units site

(6) Improved design and operation of spent fuel pool

(7) Improved instrumentation system for reactor pressure vessel and containment

(8) Revision of safety standards and guidelines, including long-term loss of external power supply against external events

(9) Enhanced operators' education and training under beyond design base conditions based on improved accident management measures

\subsection{Severe accident research related lessons}

In some investigation committee reports severe accident research related lessons learned from the Fukushima accident have been mentioned. For example, in AESJ reports, as No. 8th lesson, entitled "Lessons relating to the promotion of safety research”, as a first item “a. Severe accident research and application of its results were insufficient”, it says that "Basic safety research has not been stressed at the Japan Atomic Energy Agency, and in the future there will be a need to examine whether the agency was able to respond adequately to the recent accident.” Also as one of short-term proposals, it recommends to incorporate the existing results of severe accident research through the JAEA and Japan Nuclear Energy Safety Organization (JNES) into regulations. It also recommends the followings as long-term l proposals; systematic development of human resources relating to safety design and safety research including severe accidents, promotion of severe accident research, in particular hydrogen behavior analysis, hydrogen combustion and spent fuel pool evaluation, promotion of modeling/simulation technology, in particular raising the level of nuclear power safety and V\&V (Verification \& Validation for Simulation), and necessity to take budgetary measures and preserve research results needed in case of a disaster.

\section{RWVIEW OF SEVERE ACCIDENT RESEARCH ISSUES IN AESJ}

\subsection{SARNET Activities}

Under EU Program, European expert network for the reduction of uncertainties in severe accident safety issues (EURSAFE) has been established and it created the phenomena identification and ranking tables (PIRT) on all aspects of severe accident [8]. As one of SARNET activities, Severe Accident Research Priority (SARP) Work-Package has identified research priorities by taking as a basis of PIRT carried out in EURSAFE, and the following six issues have been considered to be investigated further with high priority [9]:

(1) Core coolability during reflood and debris cooling

(2) Ex-vessel melt pool configuration during MCCI and exvessel corium coolability by top flooding

(3) Hydrogen mixing and combustion in containment, including the effect of mitigation measures such as recombiner effect on global convection, generation of local stratification by recombiner, ignition by recombiner

(4) Melt relocation into water, ex-vessel FCI

(5) Oxidizing impact ( $\mathrm{Ru}$ oxidizing conditions/air ingress for high burn-up and MOX fuel elements) on source term

(6) Iodine chemistry in reactor cooling system (RCS) and in containment.

\subsection{AESJ Activities}

In Atomic Energy Society of Japan (AESJ) similar identification and prioritization of severe accident research issues have been reviewed by Road-map Working Group on 
severe accident in AESJ since 2009 in terms of significance of consequences, uncertainties of phenomena and maturity of assessment methodology. The first draft was drawn up as of March 8, 2011, in which weak fundamentals of thermalhydraulic safety research on LWR, such as aging of researchers in severe accident research, less young age successors for severe accident and aging of related experimental facilities, were mentioned. It also pointed out that little research has been conducted on passive hydrogen treatment system.

After the Fukushima accident re-investigation was started with the consideration of additional effects of Fukushima accident, such as core degradation behaviors, sea water injection, containment failure/leakage and re-criticality. The structure of the review results are categorized in ten major fields; core degradation behavior, core melt coolability/retention in containment vessel, function of containment vessel, source term, hydrogen behavior, fuelcoolant interaction, molten core concrete interaction, direct containment heating, recriticality and instrumentation in severe accident conditions [10].

The followings are major specific items of post-Fukushima severe accident research issues reviewed by the Working Group in AESJ:

(1) Melt/relocation behaviors of BWR core materials, such as effects of $\mathrm{B}_{4} \mathrm{C}$ control rod, interaction with spacer /channel box, debris support characteristics of core support plate, control rod guide tubes, physical properties and composition of core debris

(2) Effects of sea water injected into reactor pressure vessel on possible flow blockage due to salt deposition by boiling-off, corrosion of reactor pressure vessel wall, debris bed coolability in lower head, and two-layered molten salt and molten core

(3) Containment leakage rate beyond containment design pressure and temperature conditions

(4) Effect of sea water on iodine chemistry behavior in containment vessel

(5) Efficiency of pool scrubbing during rapid depressurization due to containment venting and during high temperature steam injection

(6) Evaluation of re-criticality in pressure vessel during reflooding after the melting of control rod with remained fuel rods geometry in core

(7) Instrumentation in severe accident conditions, such as water level measurement in pressure vessel, temperature, water level, hydrogen concentration and radiation measurements in containment vessel

It is noted that in January 2012, Research Expert Committee on Evaluation of Severe Accident was newly established in AESJ in order to investigate severe accident related issues for future LWR development and to propose action plans for future severe accident research, in collaboration with the above mentioned Working Group in AESJ. The Committee is establishing PIRT for the modeling of the analysis of Fukushima accident.

\section{IMPORTANT POST-FUKUSHIMA CHLLENGES IN SEVERE ACCIDENT RESEARCH}

As discussed in the previous chapters, there are a plenty of important severe accident research issues revealed after the Fukushima accident. Among those issues, mostly based on AESJ's activities and also author's personal view, the followings would be several most important, new or to be enhanced severe accident research issues [11] [12]:

\subsection{Investigation of damaged core and components}

In order to evaluate accident progression and damages of the core, reactor pressure vessel and containment vessel, and also to develop technical standard for the accident treatment, such as disposal of damaged core, investigation of damaged core and components are of vital importance (Possible state of Fukushima Units 1 through 3 shown in Fig. 1). The followings will be conducted to achieve the above objectives probably on the international collaboration scheme in part:

(1) Condition survey of reactor pressure vessels, containment vessels and main components

(2) Criticality control during the investigation

(3) Sample collection from damaged core, structural materials and water

(4) Detailed investigation of samples, such as metallographic observation, composition analysis, measurements of physical properties and radioactivity

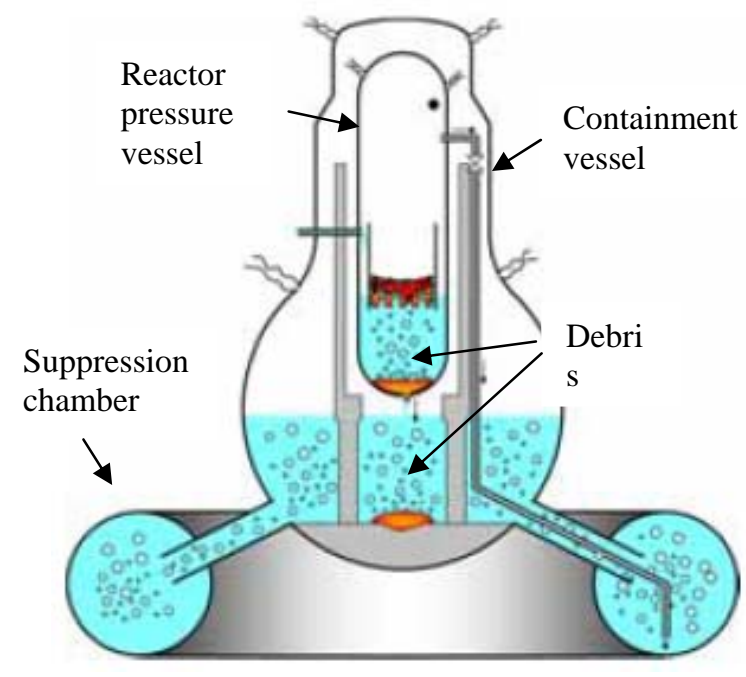

Fig. 1 Possible state of Fukushima Units 1 through 3 4.2 Advanced severe accident analysis capabilities and
associated experimental investigations 
In order to reasonably well predict severe accident progression, either in prevention or mitigation phase, advanced severe accident analysis capabilities and associated experimental investigations will be necessary. Especially invessel and ex-vessel melt coolability [13], and FP behaviors, including iodine chemistry in containment are of great importance. Relatively large scale thermal- hydraulic, fuel safety, fission product behaviors research have been conducted at national institute, for example, such as Japan Atomic Energy Agency (JAEA) as typically shown in Figs. 2 through 5, for melt coolability [14], fission product behaviors [16][17] including iodine chemistry [18] in containment, mostly past experiments [15]. Model developmental research with smallscale experiments has been and will be conducted at universities in Japan in future. In Kyoto University, small scale model experiments have been conducted to investigate the effect of hydraulics (CCFL) in the gap between RPV wall and core debris, and cracks inside core debris for in-vessel coolability and to investigate the heat transfer characteristics between porous crust above molten pool and the coolant above the crust with non-condensable gas flowing through the crust for the coolability during MCCI as typically illustrated in Figs. 6 and 7.

\section{ALPHA Program}

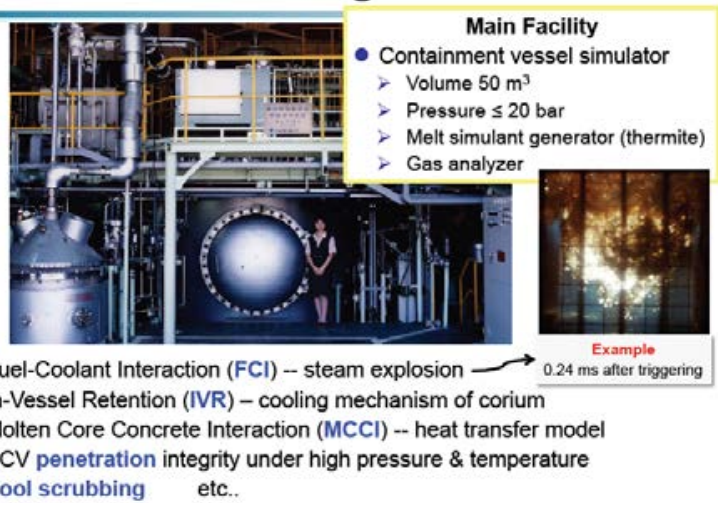

Fig. 2 ALPHA Program at JAEA [14][15]

\section{WIND Program}

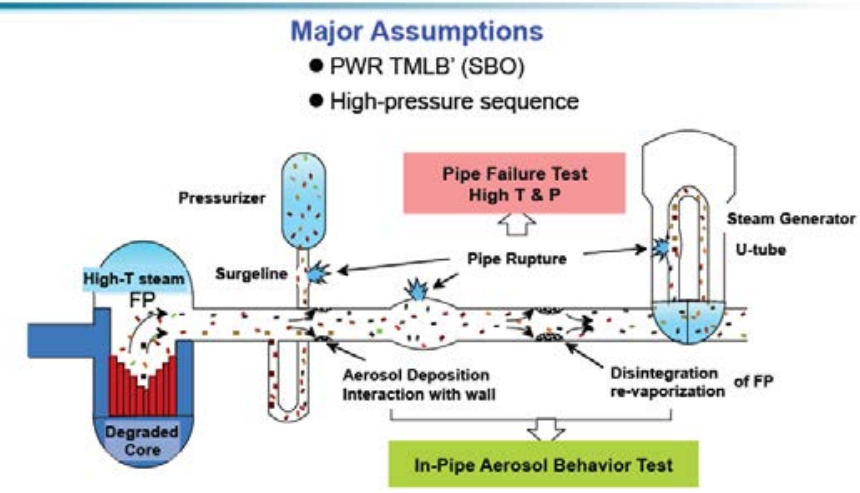

Fig. 3 WIND Program at JAEA [15][16]

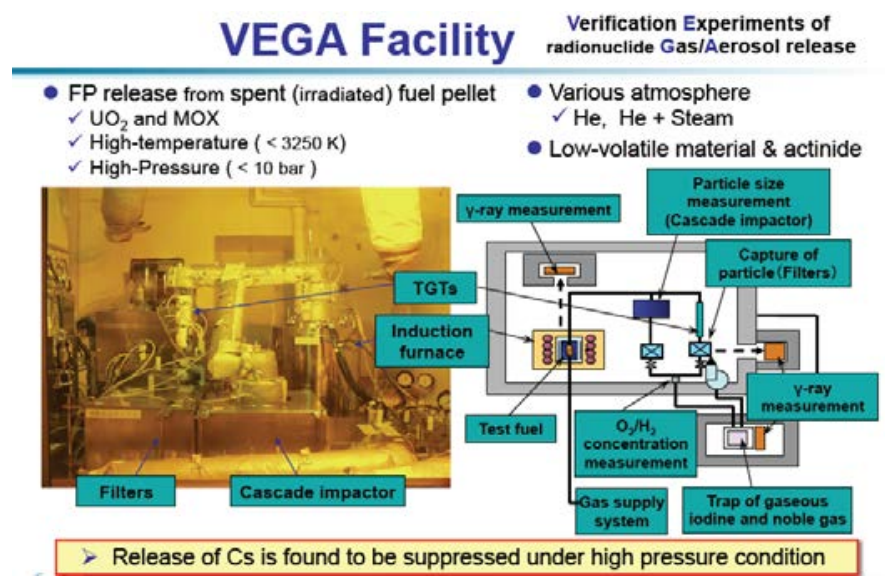

Fig. 4 VEGA Program at JAEA [15][17]

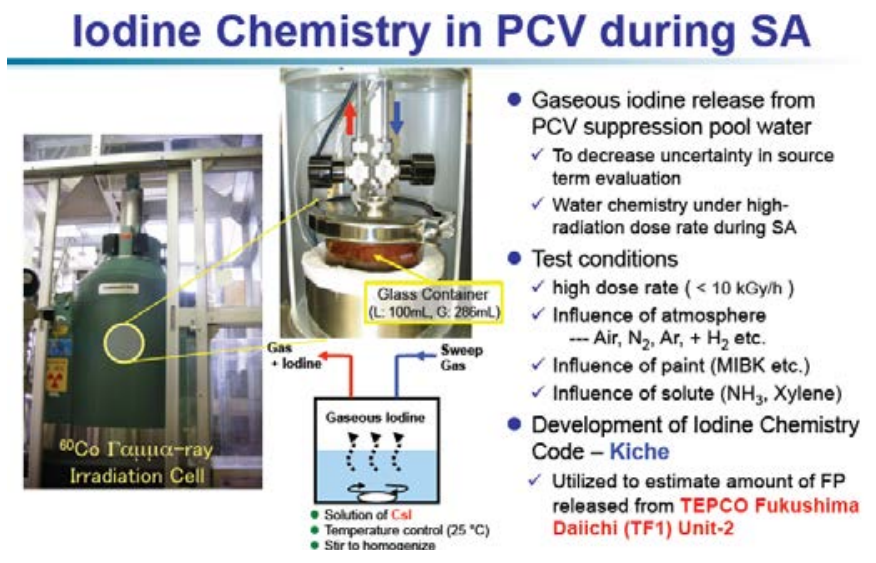

Fig. 5 Iodine Chemistry Test at JAEA [15][18]

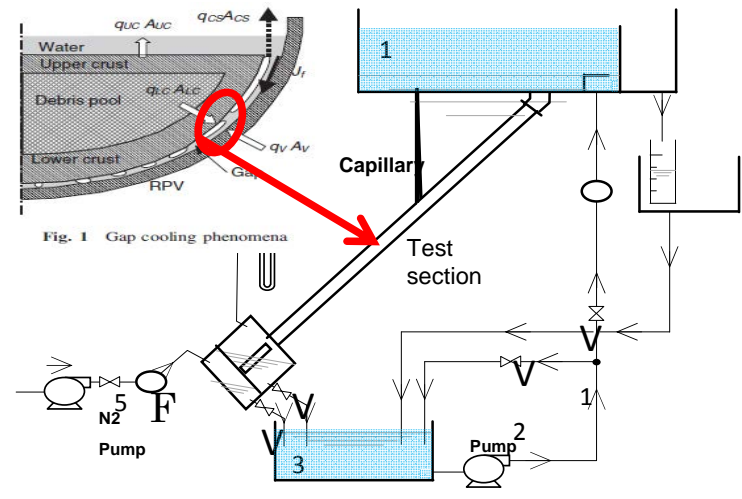

Fig. 6 CCFL experiment at Kyoto University 


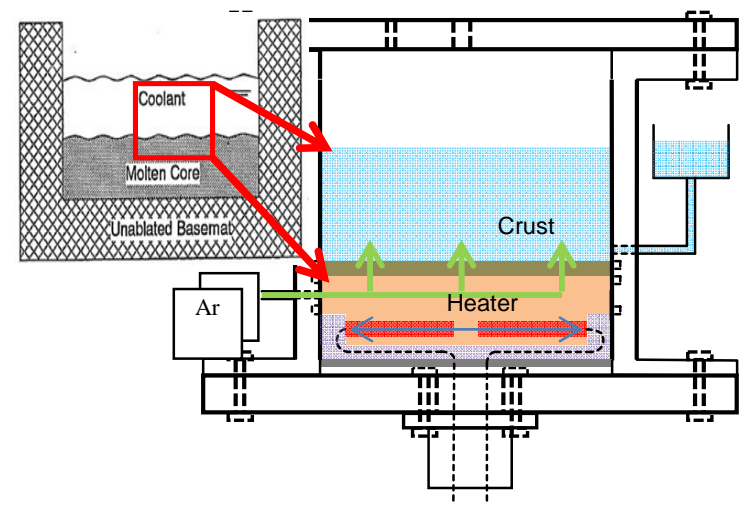

Fig. 7 MCCI experiment at Kyoto University

In analytical efforts OECD/NEA's BSAF (Benchmark Study of the Accident at the Fukushima Daiichi Nuclear Power Station) Project hosted by JAEA has been initiated among 8 countries from November 2012 using currently available severe accident analysis integral codes.

4.3 Development of reliable passive cooling system for core/containment in case of long-term station blackout

In order to cope with long-term station blackout as occurred in Fukushima accident, highly reliable passive cooling system for core and containment will be necessary for the existing and future reactors. Figure 8 shows one example of such passive cooling system being developed at University of Tsukuba without the need of power supply called "supersonic steam injector" [10].

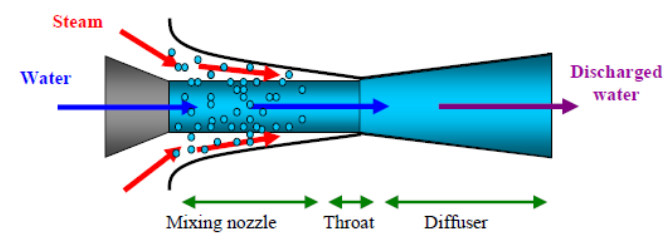

Supersonic steam injector is

- Passive water pump without electric power supply.

- High performance heat exchanger to condense steam.

- Simple, compact and low cost.

Water jet is driven by steam condensation on water jet surface, simultaneously steam is accelerated by condensation above sonic speed.

SI can be a Passive Safety System to prevent core meltdown at severe accident of nuclear power plant.

Fig. 8 Concept of supersonic steam injection [10]

\subsection{Analysis of hydrogen behavior and investigation of hydrogen measures}

In order to cope with hydrogen issues, analysis of hydrogen behaviors, such as distribution, combustion and deflagration to detonation transition (DDT) in containment and reactor building, and investigation of hydrogen measures, such as passive re-combiners or igniters will be necessary. Figure 9 shows one of such efforts by Japan Nuclear Energy Safety (JNES) [19].

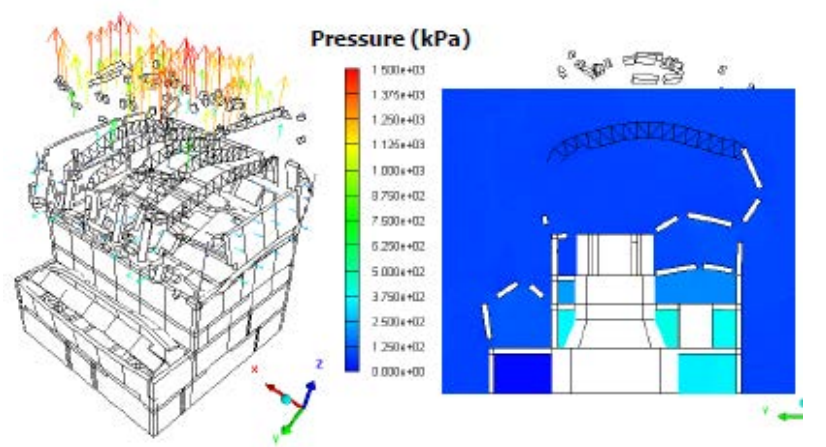

Fig. 9 Hydrogen detonation behavior [19]

\subsection{Enhancement of removal function of radioactive materials of containment venting}

In order to reduce source term drastically in case of severe accident, enhancement of removal function of radioactive materials of containment venting, including performance of filtered venting system will be important. Development of advanced filtered venting system to greatly reduce even volatile iodine will be highly expected. A new process with chemical additives by PSI has reportedly more than $10^{3}$ decontamination factor for volatile organic iodine[20].

\subsection{Advanced instrumentation for the diagnosis of severe accident}

Since there was almost no instrumentation to directly detect severe accident in Fukushima accident, it took quite a long time for plant supervisor to realize that the severe accident really happened. In order to detect and make a diagnosis of severe accident, advanced instrumentation, such as temperatures in pressure vessel, containment and base-mat concrete [21], water levels in pressure vessel and containment, hydrogen concentration and radiation measurements in containment and reactor building will be necessary.

\subsection{Assessment of advanced containment design which excludes long-term evacuation in any severe accident situations}

Even though health effect of radiation of Fukushima accident may be negligible, long-term evacuation for the residents nearby cannot be accepted by the public for the future use of nuclear. Therefore assessment of advanced containment design which excludes long-term evacuation in any severe accident situations with high confidence will be of vital importance for future. 


\section{SUMMARY}

(1) Severe accident management measures due to internal events, which were deployed in early 2000s in Japan, were apparently technically insufficient for the prevention and mitigation of Fukushima accident.

(2) Some investigation reports on Fukushima accident emphasize the importance of severe accident research and associated nuclear human resource development.

(3) For the identification and prioritization of severe accident research issues systematic approach similar to EUROSAFE has been conducted in Atomic Energy Society of Japan.

(4) Important severe accident research items should be pursued, such as investigation of damaged core, advanced severe accident analysis capabilities, development of reliable passive core cooling system, analysis of hydrogen behavior and investigation of hydrogen measures, enhancement of removal function of radioactive materials of containment venting, advanced instrumentation for the diagnosis of severe accident, and assessment of advanced containment design which excludes long-term evacuation in any severe accident situations.

\section{REFERENCES}

[1] Atomic Energy Society of Japan, Lessons learned from the accident at the Fukushima Daiichi Nuclear Power Plant, May 2011.

[2] Nuclear Emergency Response Headquarters, Government of Japan "Report of Japanese Government to the IAEA Ministerial Conference on Nuclear Safety - The Accident at TEPCO's Fukushima Nuclear Power Stations -" June 2011.

[3] Advisory Committee for Prevention of Nuclear Accident,

Recommendation from Advisory Committee for Prevention of Nuclear Accident, Dec. 2011.

[4] Independent Investigation Commission on the Fukushima Daiichi Nuclear Accident, "Investigation and Verification Report" Feb. 2012.

[5] The Tokyo Electric Power Company, Inc. "Fukushima Nuclear Accident Analysis Report (Final Report)" June 2012.

[6] National Diet of Japan Fukushima Nuclear Accident Independent Investigation Commission "Official Report" July 2012.

[7] Investigation Committee on the Accident at the Fukushima Nuclear Power Stations, July 2012.

[8] Magallon, et.al., European expert network for the reduction of uncertainties in severe accident safety issues (EURSAFE), Nuclear Engineering and Design, 235, 2005, 309-346.

[9] Jean-Pierre Van Dorsselaere, et al., Sustainable integration of EU research in severe accident phenomenology and management, Nuclear Engineering and Design, 241, 2011, 3451-3460.
[10] Abe, Y., "Phenomena Identification in Severe Accident Sequence and Safety Issues for Severe Accident Management of Light Water Reactors”, International Workshop on Nuclear Safety and Severe Accidents (NUSSA), Sept. 2012, Beijing, China.

[11] Sugimoto, J., “Japanese Perspective on Severe Accident Research after Fukushima Accident, International Workshop on Post-Fukushima Challenges in Nuclear Safety and Environmental Contamination, June 2012, Korea.

[12] Sugimoto, J., "Important Severe Accident Research Issues after Fukushima Accident", The Eighth Japan-Korea Symposium on Nuclear Thermal Hydraulics and Safety, December 2012, Beppu, Japan.

[13] Corradini, M., "Nuclear Safety: Lessons Learned after Fukushima”, NUSSA, Sept. 2012, Beijing, China.

[14] Sugimoto, J., et al., "Fuel-Coolant Interaction Experiments in ALPHA Program, Proc. 5th International Topical Meeting on Nuclear Reactor Thermal Hydraulics (NURETH-5), Salt Lake City, U.S.A., 3(1992), 890-897.

[15] Nakamura, H., "Safety Research on LWR ThermalHydraulics and Severe Accident in JAEA”, NUSSA, Sept. 2012, Beijing, China.

[16] Maruyama, Y., et al., "Vapor Condensation and Thermophoretic Aerosol Deposition of Cesium Iodide in Horizontal Thermal Gradient Pipes” J. Nucl. Sci. Technol., 36(5), 1999, 433-442.

[17] Hidaka, A., et al., "Enhancement of Cesium Release from Irradiated Fuel at Temperature above 2,800K," J. Nucl. Sci. Technol. 39(3), 2002, 273-275.

[18] Moriyama, K., et al., "Experiments on the Release of Gaseous Iodine from Gamma-Irradiated Aqueous CsI Solution and Influence of Oxygen and Methyl Isobutyl Ketone”, J. Nucl. Sci. Technol. 47(3), 2010, 229-237.

[19] Hirano, M., "Post-Fukushima Safety Research in Japan”, USNRC Regulatory Information Conference, March 2012, Washington DC, USA.

[20] Guentay, S., et al., "A Novel Process for Efficient Retention of Volatile Iodine Species in Aqueous Solutions during Reactor Accidents“, NEA/CSNI/R(2010)10

[21] Sehgal B. R., "Perception of Nuclear Power Risks Following the Fukushima Accidents", NUSSA, Sept. 2012, Beijing, China. 